\title{
HERBERTO HELDER TRADUTOR DE POÉTICAS NÃO-EUROPEIAS
}

\author{
Álvaro Faleiros ${ }^{1}$ \\ Pedro Cesarino ${ }^{1}$ \\ 1Universidade de São Paulo, São Paulo, São Paulo, Brasil
}

\begin{abstract}
Resumo: O intuito deste artigo é refletir sobre os "poema mudados para o português" do poeta Herberto Helder. Muitos deles são de poéticas não-europeias. A partir da análise de alguns poemas ameríndios, propomos discutir as implicações de suas escolhas e de como pode ser interpretada pela antropologia contemporânea.
\end{abstract}

Palavras-chave: Herberto Helder; Poemas Mudados; Poéticas Ameríndias

\section{HERBERTO HELDER TRANSLATOR OF NON-EUROPEANS POETICS}

\begin{abstract}
The purpose of this article is to reflect on the "poem changed to Portuguese" by the poet Herberto Helder. Many of them are from non-European poetics. From the analysis of some Amerindian poems, we propose to discuss the implications of their choices and how they can be interpreted by contemporary anthropology.
\end{abstract}

Keywords: Herberto Helder; Changed Poems; Amerindian Poetics

Qualquer leitor de Herberto Helder sabe que é uma constante em sua obra a retomada de obras alheias. $\mathrm{O}$ fato de Helder chamar esses seus processos de reescrita de "poemas mudados" tem sido um dos elementos mais retomados pela crítica. Essa crítica se concentra essencialmente nos cinco livros do poeta em que consta 
o termo de "poemas mudados para o português", a saber: $O$ bebedor nocturno [1961-1966], As magias [1986-1987]', Oulof [1997], Poemas ameríndios [1997] e Doze nós numa corda [1997]. Como informa Maria Estela Guedes (41), até aquele ano, "os únicos textos alienígenas estudados com alguma extensão foram os de origem bíblica". Trata-se de trabalhos referentes às reescritas de $O$ cântico dos cânticos, também parte de $O$ bebedor nocturno. É, aliás, a respeito desse trabalho que Helder (1995) faz uma de suas mais citadas observações sobre seu modo de reescrever poesia alheia:

Quanto a mim, não sei línguas. Trata-se da minha vantagem. Permite-me verter poesia do Antigo Egipto, desconhecendo o idioma, para o português. Pego no Cântico dos Cânticos, em inglês ou francês, como se fosse um poema inglês e francês, e, ousando, ouso não só um poema português como também, e, sobretudo, um poema meu. [...] O meu prazer é assim: deambulatório, ao acaso, por súbito amor, projectivo. Não tenho o direito de garantir que esses textos são traduções. Diria: são explosões velozmente laboriosas. $\mathrm{O}$ meu labor consiste em fazer com que eu próprio ajuste cada vez mais ao meu gosto pessoal o clima geral do poema já português: a temperatura da imagem, a velocidade do ritmo, a saturação atmosférica do vocábulo, a pressão do adjectivo sobre o substantivo. (Helder 68-9)

Mais recentemente, uma série de outros autores passaram a se interessar pelos "poemas mudados". Dentre eles Erick Gontijo Costa (2016) que, dialogando com a citação acima, procura mapear a dinâmica rítmica condutora de energias que animam a poética helderiana. Assim, ao se debruçar sobre a reescrita de textos Le Cézio e Henri Michaux propostas por Herberto Helder em As magias, o crítico conclui que:

${ }^{1}$ Usamos a datação presente em Toda poesia, Assírio \& Alvim, 1996. 
Parece ser esse um dos principais pontos da articulação da poética helderiana a outras: a tradução em que se mudam poemas, operando no corpo da linguagem, sem que haja aí qualquer metáfora. Trata-se de um estilo que equaciona poéticas por diferença, articulando o que nelas é por si só um elemento de diferença: o som, o movimento, o ritmo, a imagem. (Costa 49)

Rafaella Dias Fernandez (2017) parece corroborar o mesmo entendimento. Ao retomar a mesma passagem de Helder supracitada, observa que:

o poema traduzido já não é mais uma tradução, é poesia em língua portuguesa. O labor com a língua estrangeira é tão subversor, tão transformador, que o que emerge no idioma poético é uma inovação, algo que diverge em relação ao original. (Sedlmayer 203)

Sedlmayer, alguns anos antes, parece ir na mesma direção quando afirma que "o método criativo do poeta e a sinuosa reescrita que visa a atualização de vozes de escritores que, em temporalidades distintas, culturas diversas, partilharam elementos acerca de um específico saber poético". Ela chega a tal conclusão, ao observar que

Helder se detém, como tradutor, na poesia ameríndia - asteca, quíchua, yuma, sioux, omaha, navaja, na dos índios das montanhas rochosas, na dos peles-vermelhas - e também na dos esquimós, tártaros, japoneses, indonésios, árabesandaluzes e mexicanos do ciclo nauatle". (Sedlmayer 204)

Sedlmayer se coloca à escuta de toda uma tradição crítica que vê o trabalho de justaposição de Helder em suas antologias de poemas mudados, como: 
[...] a manifestação de uma preferência ou de 'afinidades electivas', que é ao mesmo tempo um retrato de família ou a invenção de uma linhagem; em suma, a cartografia de um sistema de vozes múltiplas que se afirma comunicarem entre si no que é um sistema de encontros. (Gusmão 341)

Essa poética helderiana, lembra Sedlmayer, é chamada por Maria Helena Buescu (2009) de "onívora" por ser um modo de incorporar "antropofagicamente" muitas vozes e, sobretudo, aumentar a consciência de como a tradição é construída não como fusão, mas como estranhamento. Haveria, pois, da parte de Helder:

[...] um respeito pela alteridade, mas os textos são integrados e compostos via colisão, sem preocupação em identificar a origem, data, local ou qualquer índice da condição de produção. O que parece mover Helder, completa a crítica [Buescu], é mais a determinação de 'dar a ver' as zonas obscuras, esquecidas pelo ocidente. (Sedlmayer 204).

Buescu inspira as reflexões de outro crítico interessado pelos "poemas mudados para o português". Marco Silva, ao se debruçar sobre as reescritas de Helder, destaca que "de facto, os contextos ancestrais e primitivos (sic) têm vindo a desaparecer no mundo atual, já não constituem uma referência, porque se perdem nos labirintos da tecnologia” (Silva 66). E essa chave em que lê a obra helderiana o leva a concluir que:

[...] se os Poemas Mudados para Português fossem verdadeiramente traduções, então pouco sentido acrescentariam à mundividência herbertiana, pois sabemos, em boa verdade, que tudo o que Herberto Helder produz tem um objetivo muito concreto, bem definido, que nunca sofreu desvios. Mudar para português poemas maioritariamente pertencentes às culturas ancestrais é não só valorizar esse mundo 
não contaminado, como também e principalmente atualizar, no presente, esse mundo passado. Por outras palavras, convoca-se um outro tempo, não para anular este, mas para o reconfigurar à luz daquele. Mudam-se os poemas por se compreender hoje o significado de ontem e cria-se uma terceira realidade, um novo contexto poético, uma espécie de espaço/tempo entre, que tem tanto de silencioso como de contínuo, tanto de livre como de individual, onde Herberto Helder se gosta de mover e os Poemas Mudados para Português se podem situar. (Silva 66)

Como se pode notar, há em todas essas interpretações uma adesão ao projeto poético de Herberto Helder. Nenhum dos críticos acima tentou se perguntar de onde poderiam esses textos proceder, nem em que medida se produziu textualmente uma transformação em relação a um original. Uma problematização desse lugar de partida nos parece, contudo, abrir outras possibilidades de entendimento das implicações e do alcance do projeto herbertiano.

\section{Trésor de la poésie universelle: a caverna dos ecos distantes}

Como informa Claudio Alexandre de Barros Teixeira (154), a maioria dos poemas traduzidos por Herberto Helder em $O$ bebedor nocturno baseia-se na antologia Trésor de la poésie universelle, organizada pelo sociólogo e poeta francês Roger Caillois em parceria com Jean-Clarence Lambert e publicado, no ano de 1958 em Paris, numa co-edição entre a Gallimard e a Unesco. O fato de $O$ bebedor nocturno datar do período entre 1961 e 1966 é apenas mais uma confirmação do papel matricial desse livro no projeto empreendido por Helder. Uma observação atenta da antologia de Caillois revela que a própria concepção do tipo de relação que Helder propõe tem como fonte o entendimento do que é poesia na coletânea francesa.

Em suas mais de 780 páginas, o Trésor de la poésie universelle, reúne um conjunto considerável de textos considerados poéticos, 
divindindo-os em três "Livros" segundo algumas de suas possíveis funções sociais e simbólicas. No primeiro, chamado de $O$ livro sagrado (América, África, Círculo Ártico, Polinésia, Melanésia, Ásia Central, Malásia etc.), encontram-se as seções: 1. Cantos mágicos (25-43); 2. Cantos rituais, preces, litanias (44-73); 3. Cosmogonias, mitos e lendas (74-112); 4. A epopeia sagrada (113-136); 5. As profecias (137-157); 6. Hinos e salmos (158-196). O segundo livro, chamado de Tradição e sabedoria é divido em: 1. Poesia alegórica, mística e metafísica (197-299); 2. Poesia épica e narrativa (300447); 3. Poesia solene (449-477); 4. Canções (478-516). O terceiro e último é $O$ livro lírico organizado em: 1. Egito e China antigos (517-528); 2. Grécia antiga (529-553); 3. Roma (554-580); 4. Os árabes (581-600); 5. O ocidente medieval (601-658); 6. Pérsia e Turquia (659-680); 7. As Índias (681-696); 8. A China (697-734); 9. Os vizinhos da China (735-742); 10. O Japão (743-770).

Para visualizarmos a relação existente entre $O$ bebedor nocturno e o Trésor de la poésie universelle, segue tabela com as seções do livro de Helder $^{2}$ e o lugar que ocupam os textos de partida na antologia francesa.

Tabela 1: Seções comparativas de livros

\begin{tabular}{|l|l|}
\hline O Bebedor nocturno & Trésor de la poésie universelle \\
\hline Poemas do antigo Egipto & $\begin{array}{l}\text { Ode do desesperado (517); } \\
\text { Exorcismo (42), Fragmento do } \\
\text { Cairo (522) }\end{array}$ \\
\hline Poemas do Velho Testamento & $\begin{array}{l}\text { Salmos segundo montagem de } \\
\text { Jean Gorsjean (185); Cântico dos } \\
\text { Cânticos (197-200) }\end{array}$ \\
\hline Enigmas Maias e Enigmas Astecas & Não constam \\
\hline Poesia Mexicana do ciclo Nauatle & $\begin{array}{l}\text { Elogios (469) [Os outros não } \\
\text { constam] }\end{array}$ \\
\hline Hino órfico à noite (Grécia) & $(190)$ \\
\hline
\end{tabular}

${ }^{2}$ Utilizamos a edição O bebedor nocturno, Assírio \& Alvim, 2013. 


\begin{tabular}{|l|l|}
\hline Três canções do Epiro & $(513-514)$ \\
\hline Poemas Zen & Não constam \\
\hline O mistério de Ameigen (Irlanda) & $(73)$ \\
\hline $\begin{array}{l}\text { Oração mágica finlandesa para } \\
\text { estancar o sangue das feridas }\end{array}$ & $(38)$ \\
\hline Canção escocesa & $(372)$ \\
\hline $\begin{array}{l}\text { Quatro poemas árabes e Poemas } \\
\text { arábico-andaluzes }\end{array}$ & Não constam \\
\hline Canções de camponeses no Japão & $(496)$ \\
\hline Quinze haikus japoneses & $(762-768)$ \\
\hline Poemas indochineses & $(487-488)$ \\
\hline Canções indonésias & $(485)$ \\
\hline Canção da Cabília & $(501)$ \\
\hline Canções malgaxes & $(483)$ \\
\hline Canção tártara & $(504)$ \\
\hline Cinco poemas esquimós & $(508-509) ;(37-38)$ \\
\hline Poemas dos peles vermelhas & $\begin{array}{l}\text { A puberdade (34); A obscuridade } \\
(35) ; \text { As estrelas (35) [os outros } \\
\text { seis não constam] }\end{array}$ \\
\hline
\end{tabular}

Fonte: Os autores.

Antes de compararmos alguns dos poemas para compreender o tipo de mudança operada por Herberto Helder, parece-nos relevante notar os grandes movimentos estruturais presentes na apropriação proposta pelo poeta português. Cabe, primeiro, destacar que os poemas escolhidos por Helder se situam, em sua grande maioria, entre os "Cantos mágicos e rituais" (entre as páginas 37 e 73) do início do primeiros livros e as "Canções" do segundo livro (entre as páginas 483 e 514). Soma-se a esse conjunto o "Hino órfico à noite" (Grécia); os "Salmos segundo montagem de Jean Gorsjean" (185); o "Cântico dos Cânticos" (197-200); a "Canção escocesa" e a seleção dos haikus. Com a exceção dos haikus, o que interessa a Helder são, sobretudo, cantos e cânticos mágicos e rituais. 
A ordem com que aparecem, sugere, a princípio, certa cronologia. Com efeito, parece haver uma tendência a operar a partir de um duplo eixo, temporal e espacial. Parte-se de duas grandes matrizes europeias à beira do Mediterrâneo, "Egito" e "Israel" para se atravessar o segundo grande mar europeu que é o Atlântico rumo às matrizes mais historicamente datáveis, os Astecas e Maias, anteriores aos poemas nauatle do século XV. O giro em espiral se dá pela Grécia e, salvo o interregno Zen, leva às profundezas das margens da Europa continental (Irlanda, Escócia, Finlândia e países árabes). No embarque final desde o Japão, a viagem se faz por canções distantes e não datadas, rumo aos extremos asiáticos e americanos. Nesse sentido, o projeto de Helder claramente se distancia daquele de Caillois, visto que não visa qualquer totalização, a não ser por exclusão, no caso, da Europa continental. Esse projeto, contudo, se realiza de modo paradoxal, uma vez que se dá a partir de uma língua-cultura, a francesa, marcadamente atravessada por algum desejo de universal. Um exame detido de algumas das traduções permite entrever claramente o quão o projeto de reescrita helderiano lhe é tributário.

\section{Herberto Helder tradutor dos franceses}

O primeiro dos poemas da antologia de Caillois que se encontra em $O$ bebedor Nocturno é o poema "La Puberté". Diferentemente do que ocorre em Herberto Helder que, simplesmente o enquadra entre os "Poemas dos peles vermelhas", na versão francesa ele vem acompanhado, entre parênteses, logo abaixo do título, da informação: "América do Norte. Pima". Na nota de rodapé se lê que se trata de versão francesa feita por A.-E. Preyre a partir de F. Russell. É plausível supor, pois, que já estamos diante de uma tradução francesa feita a partir do inglês, publicada como segue ${ }^{3}$ :

3 Colocamos ao lado o "poema mudado para português" para facilitar a comparação.

Cad. Trad., Florianópolis, v. 39, nº esp., p. 348-371, set-dez, 2019 
Tabela 2: Poema "La Puberté" e Tradução "A Puberdade"

\begin{tabular}{|c|c|}
\hline $\begin{array}{l}\text { LA PUBERTÉ } \\
\text { (Amérique du Nord. Pima) }\end{array}$ & A PUBERDADE \\
\hline $\begin{array}{l}\text { Sors vite, sors vite, } \\
\text { déjà descendent cette nuit les } \\
\text { échos. }\end{array}$ & $\begin{array}{l}\text { Sai depressa, depressa. } \\
\text { Já quase morrem esta noite os } \\
\text { ecos. }\end{array}$ \\
\hline $\begin{array}{l}\text { Femme vierge, femme vierge n'a } \\
\text { pas de sommeil. } \\
\text { Elle veille à travers la nuit. }\end{array}$ & $\begin{array}{l}\text { Mulher virgem, mulher virgem } \\
\text { não tem sono. } \\
\text { Vela, vela, através da noite. }\end{array}$ \\
\hline $\begin{array}{l}\text { Cactus géant brisé, gisant là : } \\
\text { mes plumes tombées se relèvent } \\
\text { plus haut que le sommet du mont } \\
\text { de la Table. }\end{array}$ & $\begin{array}{l}\text { Áspero e gigante, o cacto } \\
\text { despedaçado: } \\
\text { e minhas penas caídas elevam-se } \\
\text { no ar, } \\
\text { mais alto que o cume do monte da } \\
\text { Mesa. }\end{array}$ \\
\hline $\begin{array}{l}\text { Le garçon remua les pierres } \\
\text { grondantes; } \\
\text { la femme entendit et ne put } \\
\text { dormir. } \\
\text { Et les ongles de mes pieds sont } \\
\text { brisés. }\end{array}$ & $\begin{array}{l}\text { E eis que o jovem moveu as } \\
\text { pedras sonoras, } \\
\text { e a mulher ouviu, e não pôde } \\
\text { dormir. } \\
\text { E partiram-se as unhas de meus } \\
\text { pés. }\end{array}$ \\
\hline $\begin{array}{l}\text { Les branches de la nuit tombèrent, } \\
\text { coupant mes plumes comme je } \\
\text { passais. } \\
\text { (Caillois } 34 \text { ) }\end{array}$ & $\begin{array}{l}\text { Quando eu passava, tombaram } \\
\text { ramos da noite, } \\
\text { e quebraram-me as penas. } \\
\text { (Helder } 172 \text { ) }\end{array}$ \\
\hline
\end{tabular}

Fonte: Os autores.

Não parece haver dúvida de que a versão de Herberto Helder provém desse texto em francês. Os ajustes que se notam são muito pouco representativos para que se desconfie da procedência. Até 
em termos de pontuação e organização estrófica os textos são praticamente idênticos ${ }^{4}$.

Em termos de sintaxe e de deslocamento semântico, os ajustes mais notáveis são as inversões feitas por Helder no primeiro verso da segunda estrofe do original e na última estrofe. A primeira inversão acaba aumentando consideravelmente o grau de abstração da cena enunciativa: o cacto gigante quebrado, jazendo ali [cactus géant brisé, gisant là] perde o dêitico e deixa de "jazer" em "áspero e gigante, o cacto despedaçado". A escolha de Helder também lhe acrescenta um atributo, a aspereza, ausente em francês. A inversão na estrofe final, ao transmutar "les branches de la nuit tombèrent,/ coupant mes plumes comme je passais" por "quando eu passava, tombaram ramos da noite,/e quebraram-me as penas", torna esses versos em português muito mais claros e diretos. A introdução da conjunção coordenativa "e" no verso final também torna o enunciado mais "lógico", se comparado ao texto de partida.

A terceira mudança relevante está na tradução de "déjà descendent cette nuit les échos" por "já quase morrem esta noite os ecos". Ao traduzir "descendent" por "quase morrem", Helder produz bela imagem, mas atenua o movimento contido no verso francês. Uma tradução deste por “já descem na noite os ecos”, por exemplo, daria mais concretude à cena. Parece, pois, que o tipo de "mudança" operada por Herberto Helder acaba "ocidentalizando" ainda mais o texto, fazendo com que se distancie da canção e se aproxime do que se entende mais comumente por poema.

Esse mesmo tipo de ajuste, com os deslocamentos que implica, se encontra na grande maioria dos poemas reescritos pelo poeta português a partir do Trésor de la poésie universelle, independentemente da língua-cultura do original. Assim, no poema "esquimó" da página 37 , se lê:

\footnotetext{
${ }^{4}$ Em relação à estrutura estrófica, como no original os dois primeiros versos estão no final da página e os dois seguintes na página seguinte, talvez Herberto Helder tenha querido reproduzir o efeito visual dessa quebra que, contudo, nos parece ter sido apenas em função da paginação.
} 
Tabela 3: Poema "O Esquimó"

\begin{tabular}{|c|c|}
\hline $\begin{array}{l}\text { Esprit de l'air, } \\
\text { viens, viens vite, } \\
\text { ton conjureur t'appelle! }\end{array}$ & $\begin{array}{l}\text { Espírito do ar, vem, } \\
\text { vem de pressa. } \\
\text { O invocador te chama. }\end{array}$ \\
\hline $\begin{array}{l}\text { Viens et réduit à néant le malheur! } \\
\text { Esprit de l'air, } \\
\text { viens, viens vite! }\end{array}$ & $\begin{array}{l}\text { Vem, e purifica esta terra. } \\
\text { Espírito do ar, vem, } \\
\text { vem de pressa. }\end{array}$ \\
\hline $\begin{array}{l}\text { Je me lève, } \\
\text { c'est au milieu d'esprit que je me } \\
\text { lève. } \\
\text { Des conjureurs me soutiennent } \\
\text { et me dressent parmi des esprits. }\end{array}$ & $\begin{array}{l}\text { Levanto-me: } \\
\text { é no meio dos espíritos que eu me } \\
\text { levanto. } \\
\text { Os invocadores me protegem, } \\
\text { conduzem-me por entre os } \\
\text { espíritos. }\end{array}$ \\
\hline $\begin{array}{l}\text { Enfant, enfant, grand enfant, } \\
\text { lève-toi et accours, } \\
\text { grand enfant, petit enfant, } \\
\text { surgis parmi nous! }\end{array}$ & $\begin{array}{l}\text { Criança, criança, grande criança, } \\
\text { levanta-te e vem. } \\
\text { grande criança, pequena criança, } \\
\text { aparece entre nós. }\end{array}$ \\
\hline (Caillois 37) & (Helder 166) \\
\hline
\end{tabular}

Fonte: Os autores.

Em mais uma textualmente quase "literal" tradução do francês, Helder opera outra vez alguns poucos mas sugestivos deslocamentos. Na primeira estrofe, opta por fundir num só verso os dois últimos, o que torna, visualmente o poema mais simétrico se comparado ao francês. A ausência de qualquer transliteração do poema "esquimó" - muito provavelmente inuit, uma vez que “esquimó é um termo genérico pejorativo que designa os povos do círculo polar ártico como povos de 'pele escura' - torna contudo impossível avaliar se haveria na canção em inuktitut tais simetrias. Deixada de lado a impossibilidade de se verificar as dinâmicas do texto em inuktitut, pode-se ainda assim observar as mudanças operadas em relação ao francês. Comparando a primeira estrofe nas duas lín- 
guas europeias, destaca-se o fato de que sua 'arrumação' na versão portuguesa dá mais 'unidade semântica' à estrofe, se comparada à justaposição que a ruptura do verso em francês opera.

A comparação permite também identificar diferença em relação ao efeito dramático que a mudança na pontuação provoca. A substituição sistemática das exclamações por pontos finais diminui a ênfase dada à cena pelo texto francês. Por se tratar de uma "invocação", não é difícil supor que a presença dos pontos de exclamação visa de algum modo performá-la. Ao uniformizar a pontuação, Helder acaba neutralizando essas modulações de intensidade que a pontuação no texto de partida evoca.

A redistribuição em dois versos da repetição "viens, viens" é outro deslocamento notável na organização da dinâmica enunciativa desse canto, criando um efeito de suspensão maior em português; efeito ainda acentuado, nas estrofes seguintes, pela substituição de uma vírgula por dois pontos e pelo acréscimo de uma linha em branco separando a última estrofe do resto do poema. O procedimento adotado por Helder parece, pois, ser o de ajustar os versos no espaço, reencenando desse modo, visualmente, as respirações do texto por meio desse recurso emprestado das poéticas modernas, bastante comum entre os tradutores americanos de "etnopoesia".

No que concerne a informação semântica, é na segunda estrofe que a leitura do poeta português produz maior mudança. Ao traduzir "viens et réduit à néant le malheur!" [vem e reduz a nada o infortúnio] por "vem, e purifica esta terra", Herberto Helder apaga da canção o gesto que varre o mal [de um corpo?], relendo-o como purificação da terra.

Esse dois breves exemplos, mesmo que não permitam generalizações apressadas, lançam luz sobre alguns dos procedimentos que Herberto Helder parece adotar. É claro que, para retomar o termo de Maria Estela Guedes (2010), a "participação da antropologia" na visada de um poeta preocupado primordialmente com a elaboração de sua própria obra não será a de um antropólogo. Entretanto, tentar compreender antropologicamente e historicamente o alcance de tais escolhas talvez permita complexificar os possíveis 
modos de se relacionar com o projeto tradutório de Herberto Helder. Nesse sentido, é possível notar que, nos dois poemas produzidos em português mencionados acima, se comparados com o texto de partida francês, o que se verifica é um processo de apagamento de marcas textuais relevantes ao modo como a enunciação se encena: a supressão do dêitico e a opção por imagens mais abstratas "morrer" ao invés de "descer"; "purificar" ao invés de "varrer", " esquimós" ao invés de "inuits" - universalizam o discurso quando este, paradoxalmente, não deixa, também, de se deslocar de um olhar eurocêntrico.

É curioso e sintomático que esse olhar etnocêntrico tenha sido tomado como o seu avesso pela crítica, que considera as traduções de Helder como inventivas quando não exatamente o são, que trata sua originalidade ao se aproximar das bordas quando, neste processo, ele termina por reiterar construções poéticas que remetem mais a uma imagem construída das bordas do que às imagens e construções que elas próprias inventam para si - e com as quais a tradução que se quer não eurocêntrica deveria se confrontar. Com isso, forma-se uma imagem influente de Helder tradutor alternativo e inventivo, por oposição ao cânone, que corresponde mais bem a uma espécie de imagem projetiva e de expectativa estética deste cânone sobre um "outro" poético que não encontra correspondência em uma alteridade de sentido efetiva.

O nó é saber em que medida tal descentramento desentranha a linguagem tensionando mundos. As mudanças sintáticas propostas por Herberto Helder tendem a ser, no que concerne o Trésor de la poésie universelle, ainda mais naturalizadoras. A arrumação da sintaxe com o acréscimo de uma coordenada na última estrofe da canção dos Pima ou a fusão dos versos criando unidade semântica na estrofe inicial da invocação inuit apontam nessa direção.

Dada a grande ocorrência de poemas reescritos por Herberto Helder em $O$ bebedor nocturno a partir do Trésor de la poésie universelle - 20 das 24 seções do livro de Helder provêm dali -, o estudo detalhado de cada uma delas provavelmente trará nuanças que não cabem neste artigo, mas a proximidade dos efeitos que o 
tipo de alterações produzidas por Helder nos poemas desde o francês indicam uma tendência. Tendência essa que reverbera em seus outros livros de "poemas mudados para o português", uma vez que em quase todos eles - exceto em Doze nós numa corda - encontram-se poemas da antologia de Caillois; o que reforça o caráter matricial dessa obra.

Assim, em As magias, os cantos dos "Pigmeus da África Equatorial", "A grande rena louca" (Colômbia $\left.[\operatorname{sic}]^{5}\right)$, "Encantação" (México) e "Canto em honra dos ferreiros" (Mongólia) encontramse, respectivamente, nas páginas 44, 53, 51 e 57 do Trésor de la poésie universelle. Dos Poemas ameríndios encontram-se na antologia de Caillois: "O canto de nosso senhor o esfolado"6, "Acorda, mulher", "Perdi a pomba familiar", "O cavalo", "Lamento amoroso (índios da Amazônia)", "Beijo (índios da Amazônia)"7, "Invocação ao Sol (índios da pampa Argentina)", e "Para pedir a chuva (Araucanos)".E que se encontram, respectivamente, nas seguintes páginas do texto de partida: 179, 479, 480, 36, 492, 495, 480, 109. Em Oulof, por fim, encontra-se a narrativa huni kuin $\left(\right.$ kaxinawá $\left.^{8}\right)$, intitulada “A criação da lua" (Caillois 76-78).

\section{Reescrevendo "A criação da lua" de Capistrano de Abreu}

Diferentemente dos outros textos retomados desde o Trésor de la poésie universelle, o projeto de reescrita de "A criação da lua" se deu a partir de outro original, motivo pelo qual nele nos deteremos com vistas a tentar compreender a poética de traduzir

\footnotetext{
${ }^{5}$ No Trésor de la poésie universelle o texto é atribuído aos kwakiutl da Colômbia Britânica.

${ }^{6}$ No Trésor de la poésie universelle o texto se intitula “A Xipe Topec, Le buveur nocturne". Ou seja, o próprio título $O$ bebedor nocturno vem de um poema presente na antologia francesa.

${ }^{7}$ Em ambos os casos, Herberto Helder reproduz a mesma generalização “índios da Amazônia", "índios da pampa argentina" que se encontra no texto francês. ${ }^{8}$ Preferimos, quando não for citação, utilizar o termo Huni Kuin (Kaxinawá), modo como hoje esse povo se nomeia.
} 
elaborada por Herberto Helder. Em Oulof, o poeta português opta por, excepcionalmente, no caso de "A criação da lua", introduzir o poema com uma nota explicativa, em que se lê:

Começamos por adaptar uma versão francesa de P.-L. Ducharte, onde em nota se dizia que o texto original fora recolhido por João Capistrano de Abreu. Seguindo a pista, que era aliás despistante, chegámos ao livro rã-txa hu-niku-̃̃ - A Língua dos Caxinauás - e não a algo como Lendas, Crenças e Talismãs dos Índios da Amazônia, a que éramos francesmente induzidos - para ver que Ducharte se contentara afinal com traduzir, fornecendo-lhe uma forma poemática plana, o resumo em prosa que remata o escrito de Capistrano. (Helder 43)

Curiosamente, Helder omite a informação de que, no Trésor de la poésie universelle (Caillois 78 ) é que se encontra, em nota de rodapé, a informação de que "La création de la lune" havia sido "recueilli par J. Capistrano de Abreu, tr. Duchartre, Légendes, croyances et talismans des Indiens de l'Amazonie, Tolmer, 1923". Muito provavelmente a informação "despistante" lhe tenha sido fornecida não por Duchartre, mas por Caillois. Anedotas à parte, o que importa é que, desta vez, Helder opta por explicar sua escolha descrevendo a reescrita de Capistrano como segue:

Temos diante de nós uma poderosa dicção mítica, mágica, lírica, transgredindo em todas as frentes a norma da palavra portuguesa. Este transtorno faz-se ele mesmo e imediatamente substância e ação poéticas. A norma vem no fim, na síntese de pouco lume apanhada pelos franceses. Do descentramento de estrutura entre as duas línguas - captado com legitimidade poética - advém por si uma força expressiva instantânea em português, um português desarrumado, errado, libertado, regenerado, recriado. A fala anima-se com uma energia material jubilante. (Helder 44) 
Inspirado nessa interpretação do trabalho de Capistrano de Abreu, Helder ainda declara que: "essa fala, queremos fazê-la nossa". Mas, na prática, o que isso significa? No início da narrativa de "A lua", Capistrano de Abreu reconta":

5143. do caxinauá seu nome iôbö (feiticeiro) é.

5144. caxinauás muitos pelejaram para suas gentes ajuntaram aquelles com pelejam.

5145. do marimbondo as gentes, muito valentes muito, ali do sol do rio á beira, do marimbondo as gentes moram.

5146. caxinauás de capivara rio com moram, os caxinauás do sol do rio sovinas (ciosos) são.

O "poema mudado" por Helder, por sua vez, começa assim:

Do caxinauá seu nome seu feiticeiro é.

Caxinauás muitos pelejarem para suas gentes ajuntaram aqueles com pelejam.

Da vespa as gentes, muito valentes muito, ali do sol do rio à beira,

da vespa as gentes moram. Caxinauás de capivara rio com moram, os

caxinauás do sol do rio ciosos são.

(Helder 47)

Como o próprio Helder indica:

O trabalho na prosa transcrita conteve-se na opção de ter-

${ }^{9}$ Colocamos ao lado a versão de Helder para facilitar a comparação. 
mos ou expressões, quando Capistrano oferecia por onde optar; em manter alta voltagem quando começava a decair; em organizá-la ritmicamente numa poemática própria [...] também alternámos expressões de uso brasileiro para outras, equivalentes, de mais uso português (45).

Ao observarmos os procedimentos aqui descritos e a prática tradutória operada em $O$ bebedor nocturno, não nos parece ter havido grande distinção. Em ambos os casos, os ajustes são sobretudo de pontuação e espacialização, com alguns deslocamentos lexicais pontuais. No trecho acima, chama especial atenção o apagamento de "iôbö"; com efeito "iôbö (hoje grafado como "yube" é pajé, curador vindo da linha da jibóia ${ }^{10}$ ).

O interessante é que, mantendo-se fiel a si mesmo, Helder produza um resultado, em "A criação da lua", ambiguamente tão próximo e tão distante - inversamente proporcional - àquele que se encontra em suas versões de $O$ bebedor nocturno. Se em suas reescritas iniciais o que se verifica é um processo de domesticação sintática e normatização linguística, em "A lua” é o fascínio pela "magia" que um português supostamente "desarrumado, errado, libertado, regenerado, recriado" produz que mobiliza Helder; como se esta língua inventada por Capistrano correspondesse, de algum modo, àquilo que se entende como sendo a língua kaxinawá . O feitiço produzido por esta "obra magnífica [que] estava já feita pelos índios caxinauás" (Helder 45) desconsidera o fato de que, como bem aponta Beatriz Protti Christino, a transcrição de Capistrano era a de um linguista e tinha como objetivo servir de base para a descrição da língua kaxinawá e não para produzir literatura. A estrangeirização extrema que daí resulta, se tratada como literatura, leva a uma exotização extrema e pouco evocadora do regime de imaginação a partir de onde aquela cosmogonia vive.

${ }^{10}$ Como afirma Vivilino Mateus Inu Busẽ “Agora o pajé que é a linha da jiboia. A jiboia do antigamente, do tempo da maloca. É jiboia aquela que ensina kene, ensina a música também. É o Yube, ele é curador, é pajé”. In Oliveira (101). 
Vemos então claramente como a imagem de uma poética supostamente outra corresponde, antes, aos anseios disruptivos da própria poesia ocidental em seu confronto com seu próprio cânone. Afinal, a necessidade de desarrumação e de libertação do português, em que exatamente corresponderia às necessidades internas da poética pano que Helder não é capaz de compreender, assim como também não o foram Caillois e, ao seu modo, Capistrano? Por que ou em que, efetivamente, uma poética pano seria mágica, lírica e transgressora? Uma narrativa mítica é lírica e disruptiva para seus próprios narradores? Com relação aos seus próprios dilemas estéticos - diríamos, porque não?, pelos dilemas estéticos de uma provável e praticamente desconhecida "rede" poética amazônica - ou aos europeus?

No que se refere, mais especificamente, à suposta desarrumação sintática, torna-se mais ainda evidente que ela deriva de uma expectativa estética própria à crise do sujeito ocidental e de sua produção de sentido na linguagem. Afinal, em que exatamente seria o original pano desarrumado, quando toda língua humana se exprime pelo seu rigor, ainda mais redobrado quando se trata de um rendimento especial do discurso como o narrativo e cerimonial?

Tomemos como exemplo o seguinte fragmento da tradução de Cesarino (2013) de uma narrativa cantada saiti dos Marubo, falantes de Pano assim como os kaxinawá. Trata-se, mais especificamente, da narrativa de surgimento de Lua, uma variação próxima daquela com a qual trabalharam Capistrano e Herberto Helder. Vale dizer que os saiti são narrativas cantadas que seguem uma métrica rigorosa, por meio da qual são encadeadas fórmulas verbais transmitidas por complexos sistemas de aprendizagem. $\mathrm{Na}$ realidade, a versão marubo parece corresponder a uma espécie de gênero mais elaborado ou erudito com relação às narrativas de outros povos pano, entre os quais não é comum encontrar histórias encadeadas em longos cantos formulares (o canto de Lua, de tamanho médio, tem por volta de 500 linhas). Não é improvável que os Marubo tenham retido esse modo de composição oral que, outrora, talvez tenha sido partilhado também por outros povos da mesma fa- 
mília linguística. $\mathrm{O}$ trecho aqui reproduzido se refere ao momento em que o rapaz Temin Txoki, reduzido apenas ao seu tronco por ter sido esquartejado pelos parentes de sua esposa-espírito, retorna desolado à casa de sua mãe. Ali, ele começa a bolinar as suas irmãs que, incomodadas com o incesto, denunciam o rapaz incontinente. Proscrito, ele interpela a mãe sobre os seus possíveis destinos (no final, termina por se transformar em Lua):

\begin{tabular}{|c|c|c|}
\hline \multicolumn{3}{|l|}{ "[. } \\
\hline & Awẽ shavã tsaosho & O tronco sentado \\
\hline & Awẽ awe shavovo & Nas suas irmãs \\
\hline & Shamã shamãvãi & Ele mexe mexe \\
\hline 515. & Awẽ aki amaĩnõ & E com jenipapos \\
\hline & Nane michkivvaiki & Nas redes guardados \\
\hline & A tero tsaosho & Mãos lambuzam \\
\hline & A atõ oĩa & E dali vigiam \\
\hline & Awẽ shavã tsaosho & O tronco sentado \\
\hline 520. & Txishkekãi karãi & Que vem rastejando \\
\hline & Awẽ awe shavovo & E nas irmãs \\
\hline & Shamã shamãvãi & Ele mexe mexe \\
\hline & Awẽ aki amaĩnõ & Com jenipapos \\
\hline & Nane michkivaiki & Nas redes guardados \\
\hline 5. & A tero tsaosho & Mãos lambuzam \\
\hline & $A$ atõ oĩa & E dali vigiam \\
\hline & Txishkekãi karãi & Ele vir rastejando \\
\hline & Awẽ aki amaĩnõ & O safado então \\
\hline & Nane mevaiki & Das mãos manchadas \\
\hline & Vepastakiavo & Um tapa toma \\
\hline & Vana vana kawãi & E então lamenta \\
\hline & "Ewa mã ewa & “Mãe, minha mãe \\
\hline & $\tilde{E}$ awekatsai & Que virarei \\
\hline & Mĩ anõ chinã & Para você lembrar \\
\hline & $\tilde{E}$ teãraopa & Igarapé viro \\
\hline
\end{tabular}




\begin{tabular}{|c|c|c|}
\hline \multirow{6}{*}{540.} & Ewa mã ewa? & Mãe, minha mãe? \\
\hline & A teãnashõrao & Se igarapé virar \\
\hline & Nõ nachivarãi & Ali nos banharemos \\
\hline & Txipo kaniaivo & Os depois nascidos \\
\hline & Anõ iki añ̃vo & Assim mesmo farão \\
\hline & Iki shavánevonã & Nas épocas que virão \\
\hline \multirow{6}{*}{545.} & A awekatsai & Que virarei \\
\hline & Manã keyáraopa & Alto barranco viro \\
\hline & Ewa mã ewa? & Mãe, minha mãe? \\
\hline & A manã keyápash & Se barranco virar \\
\hline & Noke yãtávarãi & No escuro ficaremos \\
\hline & A manã keyápasho & $\mathrm{O}$ alto barranco \\
\hline \multirow{5}{*}{550.} & A noke yomeai & Nos cansará \\
\hline & Eki yoi inõvo & Para isso servirei \\
\hline & Manã keyáraopa & Se barranco virar \\
\hline & Ewa mã ewa & Mãe, minha mãe \\
\hline & $\tilde{E}$ awekatsai? & Que virarei? \\
\hline
\end{tabular}

Embora na tradução acima observe-se certo jogo com a concisão lexical e a inversão da ordem constituinte do marubo e de outras línguas pano (aglutinantes, predominantemente SOV), não se trata exatamente de reproduzir, em português, uma espécie de sintaxe truncada, marcada por interpolações de preposições e de outros recursos que criam o efeito de estranhamento proposto por Helder. $\mathrm{O}$ original pano, afinal das contas, é cristalino em seus próprios termos. Parece, assim, que o efeito projetado pelo poeta português está mais a serviço de alguma espécie de imagem primitivista das sintaxes não ocidentais, em muito afastada das qualidades gramaticais e poéticas que efetivamente marcam as fontes das quais ele se vale.

João Amadeu Oliveira Carvalho da Silva, em "a poesia de Herberto Helder entre os índios Caxinauás [sic] e a contemporaneidade brasileira", ao se referir ao uso que Helder faz das narrativas desses indígenas brasileiros, afirma que: "o diálogo com textos de culturas ancestrais [sic] não significará que exista da parte do poeta uma deslocação incondicional do sujeito, mas um condicio- 
namento de duas línguas" (136). O exemplo dos Marubo acima aponta, contudo, para a fragilidade de tal argumento, pois, como se pode observar, a "língua kaxinawá" com a qual Helder trabalha é a de um linguista operando de acordo com os padrões de registro de cem anos atrás, já bem distantes da língua que milhares de huni kuin falam e cantam diariamente ${ }^{11}$.

É claro que Herberto Helder, voz maior da poesia do século $\mathrm{XX}$, pode livremente se apropriar de qualquer outra poética para elaborar a sua. No entanto, é claro também que a invenção ocidental da liberdade estética não deve ser tomada pela invenção estética alheia e, mais ainda, considerada como referencial de acesso a poéticas outras historicamente marcadas pelo apagamento e pela distorção de suas especificidades. Outras invenções estéticas não são produzidas exatamente a partir de um excesso de significantes com relação ao significado que permitem interpretações e fruições indefinidas de versos e imagens verbais. A liberdade da apropriação poética ocidental, assim, termina em muitos casos por produzir objetos textuais (poemas) que em nada se assemelham às configurações gramaticais, estéticas e ontológicas originais, para não falar de seus regimes de autoria. Vai sem dizer, aliás, que "poemas", como se fossem efetivamente universais essa categoria e seus respectivos pressupostos, não são, em suas múltiplas origens, anônimos e coletivos, mas concebidos por outras funções-autor, que implicam também em outras circulações de significação e de especulação. Seria desejável que a crítica reconhecesse, ao menos, os desafios envolvidos em tais relações, a fim de que ofereçam avaliações mais precisas da espécie de fenômeno literário com a qual estão lidando quando comentam não apenas as traduções de Helder mas, também, os efeitos de sua recepção.

O problema é ver a crítica aderir a seu discurso de modo pouco mediado. Ignorar de onde vêm essas versões, não problematizar o jogo retórico implicado na escolha de Helder de renomear suas

${ }^{11}$ Segundo o Instituto Socioambiental, os Huni Kuin (Kaxinawá) eram, em 2014, mais de 10.000 vivendo na fronteira do Brasil com o Peru. 
"versões" para "poemas mudados"12, não se interessar se essas poéticas seguem vivas projetando-as para fora do tempo presente é apenas enfatizar o projeto criativo do grande poeta que, paradoxalmente, com seu gesto onívoro, não deixa de abrir possibilidade para que outros projetos de reescrita e outros modos de relação com as culturas indígenas se configurem desde aí, mas apenas se um olhar crítico mais aguçado não se submeter aos apagamentos temporais, espaciais e culturais que um projeto de reescrita como de Herberto Helder implica.

\section{Referências}

Buescu, Maria Helena. "Uma ideia de poesia omnívora”. Diacrítica, [s.1], 23/3 (2009), 49-63. Disponível em: http://cehum.ilch.uminho.pt/cehum/static/ publications/diacritica_23-3.pdf\#page $=49$. Acesso em 30/08/2019.

Costa, Erick Gontijo. "Articulações entre corpo, escrita, paisagem e tradução na poética de Herberto Helder”. Signo. [s.1], 41/71 (2016), 39-50. Disponível em: https://online.unisc.br/seer/index.php/signo/article/view/7071. Acesso em $30 / 08 / 2019$.

Caillois, Roger; Lambert, Jean-Clarence. Trésor de la poésie universelle. Paris, Gallimard/Unesco, 1958.

${ }^{12}$ Como bem nota Couts (61), publicado pela primeira vez, em 1968, na Portugália Editora, com o título O Bebedor Nocturno, Versões de Herberto Helder, o textobase é republicado em 1981 ainda com o título O Bebedor Nocturno, Versões. É só quando passa a integrar a edição de 1990 da Poesia Toda que Helder substitui, no título, "versões" por "poemas mudados para português". Note-se que $O$ Bebedor Nocturno não integra mais as Poesias Completas de 2004 e de 2014, nem a recolha Ofício cantante, de 2009; passando, desde 2010, a ser publicado como volume autônomo, sempre com o título $O$ Bebedor Nocturno, poemas mudados para português. 
Cesarino, Pedro de Niemeyer (Org.). Quando a Terra deixou de falar - cantos da mitologia marubo. São Paulo, Editora 34.

Christino, Beatriz Protti. A rede de Capistrano de Abreu (1853-1927): uma análise historiográfica do rã-txa hu-ni-ku-ĩ em face da Sul-americanística dos anos 1890-1929. Tese de doutorado, USP, 2006.

Couts, Patrícia Alexandra Matias Gomes dos Santos de Antunes. A Poesia Toda ou os Poemas Completos: variantes, flutuações e práticas textuais em Herberto Helder. Tese de doutorado, Universidade Nova de Lisboa, 2018.

Fernandez, Rafaella Dias. “A tradução poética na obra de Herberto Helder". Elyra, [s.1], 9 (2017),125-139. Disponível em http://www.abralic.org.br/anais/ arquivos/2014_1434480735.pdf. Acesso em 03/09/2019.

Guedes, Maria Estela. A obra ao rubro de Herberto Helder. São Paulo: Escrituras, 2010 .

Helder, Herberto. Photomaton \& vox. Lisboa: Assírio \& Alvim, 1995.

Helder, Herberto. Poesia toda. Lisboa: Assírio \& Alvim, 1996.

Helder, Herberto. Ouolof: poemas mudados para português. Lisboa: Assírio \& Alvim, 1997a.

Helder, Herberto. Poemas ameríndios: poemas mudados para português. Lisboa: Assírio \& Alvim, 1997b.

Helder, Herberto. O bebedor nocturno: poemas mudados para português. Lisboa: Assírio \& Alvim, 2013.

Oliveira, Alice Haibara. Já me transformei: modos de circulação e transformação de pessoas e saberes entre os Huni Kuin (Kaxinawá). Dissertação de mestrado, USP, 2016.

Sedlmayer, Sabrina. "Além Atlântico: a prática a tradutória de Herberto Helder”. Cadernos de Tradução, no especial 9, 2014), 198-211. Disponível em: https:// 
periodicos.ufsc.br/index.php/traducao/article/view/2175-7968.2014v3nespp198. Acesso em 03/09/2019.

Silva, Marco A. F. "Entre a tradução e a criação: Herberto Helder e os Poemas mudados para Português". Revista de Letras da Universidade Católica de Brasília. [s.1], 5.1 (2012), 59-67. Diponível em: https://portalrevistas.ucb.br/ index.php/RL/article/view/3285. Acesso em 03/09/2019.

Silva, João Amadeu Oliveira Carvalho. "A poesia de Herberto Helder entre os índios Caxinauás e a contemporaneidade brasileira". Convergência Lusíada, [s.l], 29 (2013), 131-140. Disponível em: http://rgplrc.libware.net/ojs/index.php/rcl/ article/view/206. Acesso em 29/07/2019.

Teixeira, Claudio Alexandre de Barros. A recepção da poesia japonesa em Portugal. Tese de doutorado, USP, 2014.

Recebido em: 18/09/2019 Aceito em: 05/11/2019 Publicado em dezembro de 2019

Álvaro Faleiros. E-mail: alvarofaleiros@gmail.com ORCID http://orcid.org/0000-0001-7507-7801

Pedro de Niemeyer Cesarino. E-mail: pedrocesarino@gmail.com ORCID: http://orcid.org/0000-0002-4158-7712 